\title{
Pollen-food allergy syndrome in children
}

You Hoon Jeon, MD, PhD

Department of Pediatrics, Hallym University Dongtan Sacred Heart Hospital, Hwaseong, Korea

Pollen-food allergy syndrome (PFAS) is an immunoglobulin E-mediated immediate allergic reaction caused by cross-reactivity between pollen and the antigens of foods - such as fruits, vegetables, or nuts-in patients with pollen allergy. A 42.7\% prevalence of PFAS in Korean pediatric patients with pollinosis was recently reported. PFAS is often called oral allergy syndrome because of mild symptoms such as itching, urticaria, and edema mainly in the lips, mouth, and pharynx that appear after food ingestion. However, reports of systemic reactions such as anaphylaxis have been increasing recently. This diversity in the degree of symptoms is related to the types of trigger foods and the characteristics of allergens, such as heat stability. When pediatric patients with pollen allergy are treated, attention should be paid to PFAS and an active effort should be made to diagnose it.

Key words: Pollen, Food hypersensitivity, Child

\section{Key message}

The prevalence of pollen-food allergy syndrome (PFAS) in Korean children with pollen allergy was recently reported to be $42.7 \%$. PFAS can cause a wide range of symptoms from mild allergy to severe anaphylaxis depending on the nature of food allergens that share the epitopes with pollen. Cases of anaphylaxis caused by PFAS have recently increased. Treatments for PFAS should be individualized for patients according to the severity of symptoms.

\section{Introduction}

Pollen-food allergy syndrome (PFAS) is an immunoglobulin $\mathrm{E}$ (IgE)-mediated immediate allergic reaction that occurs after ingesting fruits, vegetables, or nuts that have cross-reactivity with pollens in patients with pollinosis. PFAS is often called oral allergy syndrome because symptoms appear mainly in the lips, mouth, and pharynx. However, PFAS is a more appropriate term because the symptoms appear around the mouth as well as in the gastrointestinal tract and respiratory organs; in rare cases, it can even cause anaphylaxis. ${ }^{1,2}$ Pollen sensitization is uncommon in young children, and PFAS occurs more frequently in older children, adolescents, and adults. However, as pollen sensitization has recently increased in Korean children, ${ }^{3)}$ an interest in and examination of PFAS has become necessary in children. This article analyzes and summarizes the existing literature regarding the epidemiology, clinical patterns, causes, mechanisms, diagnosis, and treatment of PFAS.

\section{Epidemiology}

Tuft and Blumstein ${ }^{4)}$ first reported on the existence of a labile antigen in fresh fruits in 1942, while Amlot et al..$^{5)}$ first used the term "oral allergy syndrome" in 1987. The prevalence of PFAS varies among regions and pollen type. In Europe, its prevalence is reportedly $40 \%-50 \% \%^{5-7)}$ in patients with pollen allergy and approximately $20 \%$ in the Mediterranean region, a birch- and ragweed-free area. ${ }^{8)}$ The prevalence of PFAS depends on the characteristics of the target population. The prevalence of PFAS is usually determined in populations with pollen allergy or sensitization. A survey of patients with pollen allergy in Sweden reported that PFAS was present in 70\% of individuals with a birch pollen allergy and 19\% of those with other pollen allerg. ies. ${ }^{9)}$ According to Korean data, the total prevalence of PFAS was $34.6 \%$, while the prevalence of PFAS in cases of tree pollen sensitization accounted for $48 \%$ and that in patients with grass or weed pollen sensitization accounted for $13 \% .{ }^{10)}$ A recent Korean multicenter study reported that the prevalence of PFAS was $41.7 \%$ in patients with pollen allergy, $20 \%-30 \%$ in cases of sensitization to summer or autumn pollen alone, and higher than $50 \%$ in simultaneous sensitization to spring and autumn pollen or sensitization to all spring, summer, and autumn pollens. ${ }^{11)}$

Data on the prevalence of PFAS in children are limited. The prevalence of PFAS has been reported differently depending on the country, target group, and reporter. A 2014 study in Italy reported a $24 \%$ prevalence in children with allergic rhinitis by pollen. ${ }^{12)}$ In Australia in 2014, it was $14.7 \%$ in 163 patients aged 4-17 years. ${ }^{13)}$ In Mexico in 2016, it was 8.9\% in 267 children aged 6-14 years with atopic diseases. ${ }^{14)}$ In a recent nationallevel multicenter study in South Korea, the prevalence of PFAS was $42.7 \%$ in pediatric patients with pollen allergy. ${ }^{11)} \mathrm{A}$ recent

Corresponding author: You Hoon Jeon, MD, PhD. Department of Pediatrics, Hallym University Dongtan Sacred Heart Hospital, 7 Keunjaebong-gil, Hwaseong 18450, Korea 凶E-mail: jeonyouhoon@hanmail.net, https://orcid.org/0000-0002-8164-7580

Received: 6 July, 2019, Revised: 17 January, 2020, Accepted: 23 January, 2020

This is an open-access article distributed under the terms of the Creative Commons Attribution Non-Commercial License (http://creativecommons.org/licenses/bync/4.0/) which permits unrestricted non-commercial use, distribution, and reproduction in any medium, provided the original work is properly cited.

Copyright (c) 2020 by The Korean Pediatric Society 
Korean study of children with atopic dermatitis and birch pollinosis reported that the prevalence of PFAS was $43.5 \%$ in children aged 2-18 years with atopic dermatitis sensitized to birch pollens and as high as $36.6 \%$ in preschoolers aged $2-7$ years. ${ }^{15)}$ Studies on the prevalence of PFAS in children are summarized in Table 1.

\section{Clinical manifestation}

Many patients with PFAS first experience rhinoconjunctivitis because the specific IgE antibody to pollen becomes the source of cross-reactivity with the fruit or vegetable allergen. Most symptoms of PFAS are limited to the lips and oral mucosaareas that directly touch the food — but in some patients, they can progress to systemic symptoms, such as systemic urticaria, angioedema, airway edema, cough, dyspnea, vomiting, and abdominal pain (Fig. 1). One study reported that systemic symptoms other than the digestive system were noted in $8.7 \%$ of patients with PFAS, while anaphylaxis occurred in $1.7 \% .{ }^{16)} \mathrm{A}$ recent Korean multicenter study reported that PFAS caused respiratory symptoms such as coughing and dyspnea in 20.2\% of patients, digestive symptoms such as vomiting and abdominal pain in $10.7 \%$, and anaphylaxis in $8.9 \% .^{2)}$ In 2003 , a survey of PFAS for allergists was reported in the United States, and the doctors estimated a much lower prevalence than what was actually published. The authors argued that it reflects a low index of suspicion and underdiagnosis of PFAS. ${ }^{16)}$ Cases of severe systemic symptoms caused by PFAS in Korea have recently increased. Therefore, physicians must pay special attention to this issue.

\section{Cross-reactivity between pollen and food}

PFAS is a phenomenon that occurs because of cross-reactivity between pollen and food. Cross-reactivity occurs when allergens share epitopes. Pollen-specific IgE can recognize homologous food allergens that share the same epitopes. ${ }^{1,17-20)}$ Birch pollen, a representative spring pollen, shows cross-reactivity with many food allergens but more frequently with members of the Rosaceae family, such as apple, pear, sweet cherry, peach, plum, apricot, and almond. Apple has such a prominent clinical relevance with birch that the term apple-birch syndrome is in use. It also has cross-reactivity with celery, carrot, potato, kiwifruit, hazelnut, and mango. In a recent domestic study, the food that caused PFAS most frequently in children aged 7 years or older

Table 1. Summary of studies on the prevalence of pollen-food allergy syndrome in children

\begin{tabular}{lllcc}
\hline Study & Nation & \multicolumn{1}{c}{ Target population } & Age (yr) & Participant \\
\hline Dondi et al. $^{12)}$ & Italy & Pollen-induced AR & $4-18$ & $1,360(2009-2011)$ \\
Brown et al. $^{13)}$ & Australia & Seasonal AR & $3.4-18.6$ & $120(2014)$ \\
Kim et al. $^{11)}$ & Korea & AR, AC, BA with pollen sensitization & $<18$ & $300(2016)$ \\
Kim et al. $^{15)}$ & Korea & AD with birch sensitization & 2-18 & 186 (2016)
\end{tabular}

PFAS, pollen-food allergy syndrome; AR, allergic rhinitis; AC, allergic conjunctivitis; BA, bronchial asthma; $A D$, atopic dermatitis.

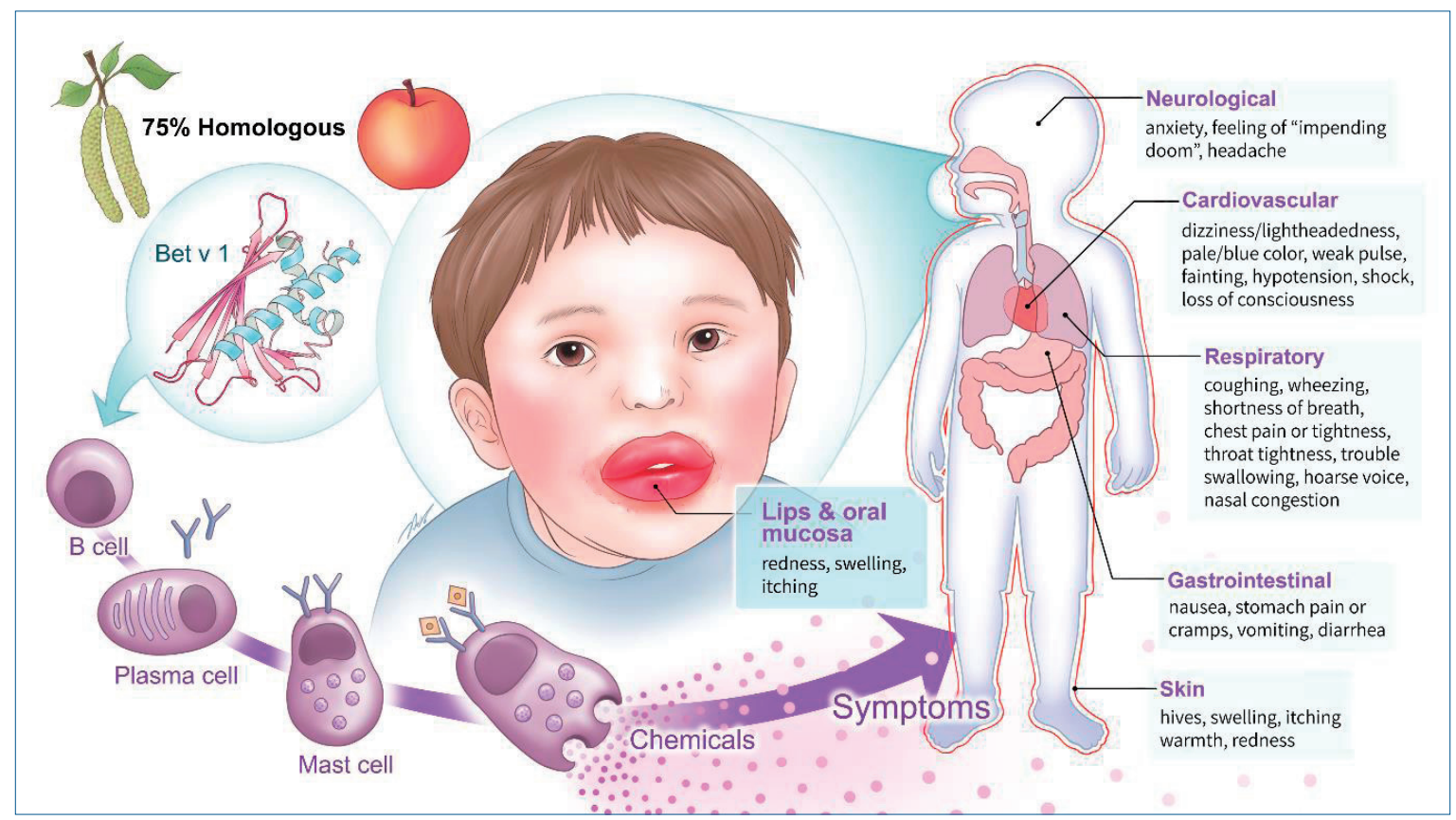

Fig. 1. The symptoms of pollen-food allergy syndrome primarily include a rash or itching sensation around the lips; however, it can also cause systemic symptoms such as a whole-body rash, respiratory difficulty, coughing, wheezing, vomiting, abdominal pain, low blood pressure or paleness, headache, and dizziness. 


\begin{tabular}{|c|c|}
\hline Pollen & Food \\
\hline Birch & $\begin{array}{l}\text { Rosaceae (apple, pear, sweet cherry, peach, plum, apricot, almond), Apiaceae (celery, carrot), Solanaceae (potato), Actinidiaceae (kiwifruit), } \\
\text { Betulaceae (hazelnut), Anacardiaceae (mango), chili pepper }\end{array}$ \\
\hline Grass & Cucurbitaceae (melon, watermelon), Solanaceae (tomato, potato), Actinidiaceae (kiwifruit), Rutaceae (orange), Fabaceae (peanut) \\
\hline Ragweed & Cucurbitaceae (melon, watermelon, cantaloupe, zucchini, cucumber), Musaceae (banana) \\
\hline Mugwort & Apiaceae (celery, carrot), Anacardiaceae (mango), spice \\
\hline
\end{tabular}

Table 3. Antigens causing pollen-food allergy syndrome

\begin{tabular}{|c|c|c|}
\hline Protein family & Pollen allergens & Class 2 food allergens \\
\hline $\begin{array}{l}\text { PR-10 } \\
\text { (Bet } \vee 1 \text { group) }\end{array}$ & $\begin{array}{l}\text { Aln g } 1 \text { (alder), Bet v } 1 \text { (birch), Cas s } 1 \\
\text { (chestnut), Cor a } 1 \text { (hazelnut), Que a } 1 \\
\text { (white oak), }\end{array}$ & $\begin{array}{l}\text { Api g } 1 \text { (celery), Ara h } 8 \text { (peanut), Cor a } 1 \text { (hazelnut), Dau c } 1 \text { (carrot), Fra a } 1 \\
\text { (strawberry), Gly m } 4 \text { (soybean), Mal d } 1 \text { (apple), Pru ar } 1 \text { (apricot), Pru av } 1 \text { (sweet } \\
\text { cherry), Pyr c } 1 \text { (pear), Sol t } 1 \text { (potato) }\end{array}$ \\
\hline Profilin & $\begin{array}{l}\text { Art v } 4 \text { (mugwort), Bet v } 2 \text { (birch), } \\
\text { Cyn d } 12 \text { (Bermuda grass), Phl p } 12 \\
\text { (timothy) }\end{array}$ & $\begin{array}{l}\text { Ana c } 1 \text { (pineapple), Ara h } 5 \text { (peanut), Api g } 4 \text { (celery), Cor a } 2 \text { (hazelnut), Cuc } m 2 \\
\text { (muskmelon), Gly m } 3 \text { (soybean), Lyc e } 1 \text { (tomato), Mus xp } 1 \text { (banana), Pru av } 4 \\
\text { (sweet cherry), Pru p } 4 \text { (peach), Pyr c } 4 \text { (pear) }\end{array}$ \\
\hline PR-14 (LTP) & $\begin{array}{l}\text { Art v } 3 \text { (mugwort), Cas s } 8 \text { (chestnut), } \\
\text { Pla a } 3 \text { (plane tree), Heb b12 (latex) }\end{array}$ & $\begin{array}{l}\text { Aspa o } 1 \text { (asparagus), Bra o } 3 \text { (cabbage), Cit I } 3 \text { (lemon), Cit s } 3 \text { (sweet orange), } \\
\text { Fra a } 3 \text { (strawberry), Lac s } 1 \text { (lettuce), Lyc e } 3 \text { (tomato), Mal d } 3 \text { (apple), Prua r } 3 \\
\text { (apricot), Prua v } 3 \text { (sweet cherry), Pru d } 3 \text { (European plum), Pru p } 3 \text { (peach), Vit v } \\
1 \text { (grape), Zea m } 14 \text { (maize, corn), Cor a } 8 \text { (hazelnut), Jug r } 3 \text { (English walnut) }\end{array}$ \\
\hline
\end{tabular}

PR-10, pathogenesis-related protein 10; LTP, lipid transfer protein.

Data from http://fermi.utmb.edu/SDAP/.

with atopic dermatitis sensitized to birch was apple and the most frequent food was kiwifruit in children aged 2-7 years. ${ }^{15)}$ Grass, a summer pollen, shows cross-reactivity with melon, watermelon, tomato, potato, kiwifruit, orange, and peanut. An autumn pollen, ragweed has cross-reactivity with melon, watermelon, cantaloupe, zucchini, cucumber, and banana, while mugwort has cross-reactivity with celery, carrot, mango, and spices. ${ }^{15,21-25)}$ The PFAS caused by cross-reactivity between autumn pollen and various foods is called celery-mugwort-spices syndrome and ragweed-melon-banana syndrome (Table 2). ${ }^{26}$

\section{Antigens causing PFAS}

Food allergens causing IgE sensitization in IgE-mediated food allergy are divided into 2 classes by the sensitization pathway. For class 1 food allergens, IgE sensitization occurs after exposure through the gastrointestinal tract. All foods can belong to this class, but major ones are eggs, milk, peanuts, nuts, fish, soybeans, wheat, and crustaceans, which are the major causes of food allergies in infants and children and often lead to systemic reactions or anaphylaxis. Class 2 food allergens are structurally homologous with plant proteins such as pollen allergens sensitized through the respiratory organs. They cause problems mostly after adolescence and mainly cause mild symptoms or PFAS. However, systemic reactions cannot be excluded and anaphylaxis may occur depending on the allergen and individual. ${ }^{25}$ )

Allergens causing PFAS are largely classified into pathogenesisrelated protein (PR)-10 family, profilin, lipid transfer protein (LTP), and cross-reactive carbohydrate determinants (CCD) (Table 3).25) The PR-10 family is the most important and representative allergen causing PFAS. Bet $\mathrm{v} 1$, a major allergen of birch, belongs to this family. Hence, it is also called the "Bet v 1 group." This protein increases when plants are in a stressful situation and exists in most foods. Mal d 1 of apple, Pru ar 1 of apricot, and Pru av 1 of sweet cherry belong to the Bet $\mathrm{v} 1$ group and cause cross-reactivity between birch pollen and Rosaceae family fruits. ${ }^{2,21,25)}$ Bet $\mathrm{v} 1$ often causes symptoms limited to the mouth because it easily loses antigenicity upon exposure to heat and digestive enzymes.

In contrast, Api g 1 of celery and Gly m 4 of soybean are allergens that mainly cause systemic symptoms despite belonging to the same PR-10 family. Celery and soybean allergies are reportedly accompanied by systemic reactions, including anaphylaxis, in more than half of sensitized patients. Api g 1, the main allergen of celery, is strong against heat, and Gly $\mathrm{m} 4$, the main allergen of soybean, is vulnerable to fermentation but strong against heat. The characteristics of these allergens seem to cause severe allergic reactions. ${ }^{27-30)}$

Profilin, an actin-binding protein of $12-15 \mathrm{kDa}$, is involved in maintaining the cytoskeleton. It exists in a variety of plants and foods. Bet v 2 of birch, Art v 4 of mugwort, and Api g 4 of celery belong to this family. 221,25$)$ The cross-reactivity of celery-birch/ mugwort-spices, grass pollen-celery-carrots, and tree pollenhazelnut is caused by profilin. ${ }^{31-33)}$ Similar to Bet $\mathrm{v} 1$, the antigenicity of profilin is decreased by heat and digestive enzymes. ${ }^{2}$

LTP belongs to the PR-14 family. Examples include Art v 3 of mugwort, Pru $\mathrm{p} 3$ of peach, Pru ar 3 of apricot, Pru av 3 of sweet cherry, and Mal d 3 of apple.,2,25) Unlike most other allergens causing PFAS, LTP is stable to heat and digestive enzymes and can cause class 1 or class 2 food allergies. ${ }^{16,34)}$ The stability of LTP makes it reach the gastrointestinal immune system and enable an allergenic conformation, and it can cause sensitization and systemic symptoms. As a result, LTP can more easily cause severe 
systemic reactions, such as systemic urticaria, angioedema, dyspnea, and anaphylaxis, than the PR-10 family. ${ }^{35,36)}$ Severe allergic reactions by LTP are often triggered by physical exercise and nonsteroidal anti-inflammatory medications. ${ }^{37}$

CCD, a glycoprotein that contains $\mathrm{N}$-linked glycan and has IgE-binding ability, can cause wide-ranging cross-reactivity with different species. It exists in celery, tomato, potato, peanut, ragweed, and birch. However, it is unclear whether all of these antigens cause clinical symptoms. ${ }^{30,32,38)}$

\section{Diagnosis}

The most important factor in diagnosing PFAS is to collect a detailed history. Skin prick tests (SPTs) and serum-specific IgE antibody measurements show large differences in sensitivity and specificity depending on the type of trigger foods. The commercial food extracts used in SPTs can cause unexpected protein denaturation in the antigen manufacturing process and show relatively low sensitivity and specificity in the SPTs of fruits and vegetables. Therefore, a prick-to-prick test is sometimes used, which directly tests the individual using fresh fruits and vegetables. In general, for apple, orange, tomato, carrot, celery, sweet cherry, and peach, the prick-to-prick test shows higher specificity and sensitivity than SPTs using a commercial food extract or serum-specific IgE antibody measurement using a radioallergosorbent test. ${ }^{39,40)} \mathrm{A}$ component-resolved diagnosis using microarray techniques can also be used, but it remains difficult to distinguish between a sensitization and a true allergy. ${ }^{41)}$ If the findings of a clinical history and allergy test are ambiguous, PFAS can be confirmed through an oral food challenge test. ${ }^{25}$

\section{Treatment}

The primary treatment of PFAS is to avoid the trigger foods. ${ }^{42)}$ Food allergies were reportedly lost in approximately one third of some adult patients after the complete restriction of trigger foods for 2 years. However, the general opinion is that food restriction cannot be a treatment to fundamentally eradicate PFAS because pollen, rather than food allergens, causes the cross-reactivity. Heating the trigger foods before eating them can be another solution because most fruits and vegetables causing PFAS are vulnerable to heat, which decreases allergenicity. ${ }^{1,43-45)}$ However, this requires caution because heating is not effective for heat-stable allergens such as those in the LTP family, Api g 1 of celery, and Gly $\mathrm{m} 4$ of soybean. Furthermore, to the contrary, when peanuts are roasted, allergenicity increases because the IgE-binding capacity of the main allergens of peanuts, Ara h 1 and Ara h 2, increases. ${ }^{1)}$ Risk factors for systemic symptoms include a history of systemic reactions to one of the related foods, reactions to cooked form of the food, positive reaction in the SPT with a commercial food extract, no sensitization to relevant pollen allergens, and peach allergy. ${ }^{16)}$ For patients with PFAS and a history of anaphylaxis, a self-injectable epinephrine should be prescribed. ${ }^{31)}$ The role of immunotherapy as a treatment for PFAS is controversial. One study found that $84 \%$ of patients experienced the disappearance or significant reduction of apple allergies after immunotherapy with birch pollen extract. However, 30 months after the cessation of immunotherapy, many patients showed a tendency toward recurrence. ${ }^{45,46)}$ Some studies have reported improved symptoms of food allergies after pollen immunotherapy, whereas others have failed to prove their effects. $^{47-50)}$

\section{Conclusion}

The prevalence of PFAS in Korean children with pollen allergy was recently reported to be $42.7 \%$. In a study of children sensitized to birch pollens, the prevalence was as high as $36.6 \%$ in those aged 2-7 years. Furthermore, a recent multicenter study in Korea reported that the incidence of anaphylaxis was 8.9\% in patients with PFAS, which is much higher than that reported in the past. PFAS has not received much attention historically because physicians have considered it a mild transient disease. However, our findings demonstrate that pediatric patients with pollen allergy should be interviewed in detail to screen for PFAS. In cases of doubt, an active examination is required. Treatments for PFAS should be individualized for patients because it can cause a wide range of symptoms from mild allergy to severe anaphylaxis.

\section{Conflicts of interest}

No potential conflict of interest relevant to this article was reported.

See the commentary "Insights into pediatric pollen food allergy syndrome” via https://doi.org/10.3345/cep.2019.01179.

\section{References}

1. Price A, Ramachandran S, Smith GP, Stevenson ML, Pomeranz MK, Cohen DE. Oral allergy syndrome (pollen-food allergy syndrome). Dermatitis 2015;26:78-88.

2. Webber CM, England RW. Oral allergy syndrome: a clinical, diagnostic, and therapeutic challenge. Ann Allergy Asthma Immunol 2010;104:1018 .

3. Kim JH, Oh JW, Lee HB, Kim SW, Kang IJ, Kook MH, et al. Changes in sensitization rate to weed allergens in children with increased weeds pollen counts in Seoul metropolitan area. J Korean Med Sci 2012;27:3505.

4. Tuft L, Blumstein GI. Studies in food allergy: II. sensitization to fresh fruits: clinical and experimental observations. J Allergy 1942;13:574-82.

5. Amlot PL, Kemeny DM, Zachary C, Parkes P, Lessof MH. Oral allergy syndrome (OAS): symptoms of IgE-mediated hypersensitivity to foods. Clin Allergy 1987;17:33-42.

6. Bircher AJ, Van Melle G, Haller E, Curty B, Frei PC. IgE to food allergens are highly prevalent in patients allergic to pollens, with and without symptoms of food allergy. Clin Exp Allergy 1994;24:367-74.

7. Osterballe M, Hansen TK, Mortz CG, Bindslev-Jensen C. The clinical 
relevance of sensitization to pollen-related fruits and vegetables in unselected pollen-sensitized adults. Allergy 2005;60:218-25.

8. Cuesta-Herranz J, Lázaro M, Figueredo E, Igea JM, Umpiérrez A, De-LasHeras M. Allergy to plant-derived fresh foods in a birch- and ragweed-free area. Clin Exp Allergy 2000;30:1411-6.

9. Eriksson NE, Formgren H, Svenonius E. Food hypersensitivity in patients with pollen allergy. Allergy 1982;37:437-43.

10. Cho YS, Lim YJ, Lee JC, Kim SH, Lim MK, Yoo B, et al. Oral allergy syndrome in pollen - sensitized patients. J Asthma Allergy Clin Immunol 1998;18:458-65.

11. Kim MA, Kim DK, Yang HJ, Yoo Y, Ahn Y, Park HS, et al. Pollen-food allergy syndrome in Korean pollinosis patients: a nationwide survey. Allergy Asthma Immunol Res 2018;10:648-61.

12. Dondi A, Tripodi S, Panetta V, Asero R, Businco AD, Bianchi A, et al. Pollen-induced allergic rhinitis in 1360 Italian children: comorbidities and determinants of severity. Pediatr Allergy Immunol 2013;24:742-51.

13. Brown $\mathrm{CE}$, Katelaris $\mathrm{CH}$. The prevalence of the oral allergy syndrome and pollen-food syndrome in an atopic paediatric population in southwest Sydney. J Paediatr Child Health 2014;50:795-800.

14. Bedolla-Barajas M, Kestler-Gramajo A, Alcalá-Padilla G, MoralesRomero J. Prevalence of oral allergy syndrome in children with allergic diseases. Allergol Immunopathol (Madr) 2017;45:127-33.

15. Kim KI, Lee B, Min TK, Lee J, Pyun BY, Jeon YH. Clinical characteristics of oral allergy syndrome in children with atopic dermatitis and birch sensitization: a single center study. J Korean Med Sci 2019;34:e11.

16. Ma S, Sicherer SH, Nowak-Wegrzyn A. A survey on the management of pollen-food allergy syndrome in allergy practices. J Allergy Clin Immunol 2003;112:784-8.

17. Sicherer SH. Clinical implications of cross-reactive food allergens. J Allergy Clin Immunol 2001;108:881-90.

18. Kazatsky AM, Wood RA. Classification of food allergens and crossreactivity. Curr Allergy Asthma Rep 2016;16:22.

19. Valenta R, Kraft D. Type 1 allergic reactions to plant-derived food: a consequence of primary sensitization to pollen allergens. J Allergy Clin Immunol 1996;97:893-5.

20. Ebner C, Birkner T, Valenta R, Rumpold H, Breitenbach M, Scheiner O, et al. Common epitopes of birch pollen and apples: studies by western and northern blot. J Allergy Clin Immunol 1991;88:588-94.

21. Breiteneder H, Ebner C. Molecular and biochemical classification of plant-derived food allergens. J Allergy Clin Immunol 2000;106(1 Pt 1): 27-36.

22. Wensing M, Akkerdaas JH, van Leeuwen WA, Stapel SO, BruijnzeelKoomen CA, Aalberse RC, et al. IgE to Bet v 1 and profilin: cross-reactivity patterns and clinical relevance. J Allergy Clin Immunol 2002;110: 435-42.

23. Kazemi-Shirazi L, Pauli G, Purohit A, Spitzauer S, Fröschl R, HoffmannSommergruber K, et al. Quantitative IgE inhibition experiments with purified recombinant allergens indicate pollen-derived allergens as the sensitizing agents responsible for many forms of plant food allergy. J Allergy Clin Immunol 2000;105(1 Pt 1):116-25.

24. Hofmann A, Burks AW. Pollen food syndrome: update on the allergens. Curr Allergy Asthma Rep 2008;8:413-7.

25. Kondo Y, Urisu A. Oral allergy syndrome. Allergol Int 2009;58:485-91.

26. Möller C. Effect of pollen immunotherapy on food hypersensitivity in children with birch pollinosis. Ann Allergy 1989;62:343-5.

27. Lüttkopf D, Ballmer-Weber BK, Wüthrich B, Vieths S. Celery allergens in patients with positive double-blind placebo-controlled food challenge. J Allergy Clin Immunol 2000;106:390-9.

28. Ballmer-Weber BK, Vieths S, Lüttkopf D, Heuschmann P, Wüthrich B. Celery allergy confirmed by double-blind, placebo-controlled food challenge: a clinical study in 32 subjects with a history of adverse reactions to celery root. J Allergy Clin Immunol 2000;106:373-8.

29. Mittag D, Vieths S, Vogel L, Becker WM, Rihs HP, Helbling A, et al. Soybean allergy in patients allergic to birch pollen: clinical investigation and molecular characterization of allergens. J Allergy Clin Immunol 2004;113:148-54.

30. Ebo DG, Hagendorens MM, Bridts CH, De Clerck LS, Stevens WJ.
Sensitization to cross-reactive carbohydrate determinants and the ubiquitous protein profilin: mimickers of allergy. Clin Exp Allergy 2004;34:13744.

31. Choi JH, Lee CY. Oral allergy syndrome. Allergy Asthma Respir Dis 2018;6:85-9.

32. Egger M, Mutschlechner S, Wopfner N, Gadermaier G, Briza P, Ferreira F. Pollen-food syndromes associated with weed pollinosis: an update from the molecular point of view. Allergy 2006;61:461-76.

33. Ballmer-Weber BK, Vieths S, Lüttkopf D, Heuschmann P, Wüthrich B. Celery allergy confirmed by double-blind, placebo-controlled food challenge: a clinical study in 32 subjects with a history of adverse reactions to celery root. J Allergy Clin Immunol 2000;106:373-8.

34. Asero R, Mistrello G, Roncarolo D, de Vries SC, Gautier MF, Ciurana $\mathrm{CL}$, et al. Lipid transfer protein: a pan-allergen in plant-derived foods that is highly resistant to pepsin digestion. Int Arch Allergy Immunol 2000; 122:20-32.

35. van Ree R. Clinical importance of non-specific lipid transfer proteins as food allergens. Biochem Soc Trans 2002;30(Pt 6):910-3.

36. Midoro-Horiuti T, Brooks EG, Goldblum RM. Pathogenesis-related proteins of plants as allergens. Ann Allergy Asthma Immunol 2001;87: 261-71.

37. Pascal M, Muñoz-Cano R, Reina Z, Palacín A, Vilella R, Picado C, et al. Lipid transfer protein syndrome: clinical pattern, cofactor effect and profile of molecular sensitization to plant-foods and pollens. Clin Exp Allergy 2012;42:1529-39.

38. Mari A, Iacovacci P, Afferni C, Barletta B, Tinghino R, Di Felice G, et al. Specific IgE to cross-reactive carbohydrate determinants strongly affect the in vitro diagnosis of allergic diseases. J Allergy Clin Immunol 1999; 103:1005-11.

39. Ortolani C, Ispano M, Pastorello EA, Ansaloni R, Magri GC. Comparison of results of skin prick tests (with fresh foods and commercial food extracts) and RAST in 100 patients with oral allergy syndrome. J Allergy Clin Immunol 1989;83:683-90.

40. Osterballe M, Scheller R, Stahl Skov P, Andersen KE, Bindslev-Jensen C. Diagnostic value of scratch-chamber test, skin prick test, histamine release and specific IgE in birch-allergic patients with oral allergy syndrome to apple. Allergy 2003;58:950-3.

41. Ebo DG, Bridts CH, Verweij MM, De Knop KJ, Hagendorens MM, De Clerck LS, et al. Sensitization profiles in birch pollen-allergic patients with and without oral allergy syndrome to apple: lessons from multiplexed component-resolved allergy diagnosis. Clin Exp Allergy 2010;40:33947.

42. Sloane D, Sheffer A. Oral allergy syndrome. Allergy Asthma Proc 2001; 22:321-5.

43. Barbi E, Berti I, Longo G. Food allergy: from the of loss of tolerance induced by exclusion diets to specific oral tolerance induction. Recent Pat Inflamm Allergy Drug Discov 2008;2:212-4.

44. Clark AT, Skypala I, Leech SC, Ewan PW, Dugué P, Brathwaite N, et al. British Society for Allergy and Clinical Immunology guidelines for the management of egg allergy. Clin Exp Allergy 2010;40:1116-29.

45. Pastorello EA, Stocchi L, Pravettoni V, Bigi A, Schilke ML, Incorvaia C, et al. Role of the elimination diet in adults with food allergy. J Allergy Clin Immunol 1989;84(4 Pt 1):475-83.

46. Asero R. Effects of birch pollen-specific immunotherapy on apple allergy in birch pollen-hypersensitive patients. Clin Exp Allergy 1998;28:136873.

47. Asero R. How long does the effect of birch pollen injection SIT on apple allergy last? Allergy 2003;58:435-8.

48. Asero R. Fennel, cucumber, and melon allergy successfully treated with pollen-specific injection immunotherapy. Ann Allergy Asthma Immunol 2000;84:460-2.

49. Mari A, Ballmer-Weber BK, Vieths S. The oral allergy syndrome: im proved diagnostic and treatment methods. Curr Opin Allergy Clin Immunol 2005;5:267-73.

50. Kelso JM, Jones RT, Tellez R, Yunginger JW. Oral allergy syndrome successfully treated with pollen immunotherapy. Ann Allergy Asthma Immunol 1995;74:391-6. 
How to cite this article: Jeon YH. Pollen-food allergy syndrome in children. Clin Exp Pediatr 2020;63:463-8. https:// doi.org/10.3345/cep.2019.00780 